\title{
Budget Constraints and the Management of Education Credits in Cameroon: Pathways to Efficiency and Sustainability
}

\section{Prosper Mbelle Mekolle}

Department of Educational Foundations and Administration, Faculty of Education, University of Buea, Cameroon mekolle.mbelle@ubuea.cm

\begin{abstract}
This study inquired into the educational management strategies that generate best possible outcomes with a given amount of resources. It birthed from the need to attempt solution to the apparent inefficiencies that characterize educational institutions in Cameroon and in other countries in the world. Attention was on secondary education. The research adopted the survey design, specifically the qualitative method. The simple random sampling technique was used to select a sample of 13, from a total of 18 secondary schools-public and private of the English sub-system of education that consistently scored high (above 95\%) in the Cameroon General Certificate of Education (GCE) Examination-Ordinary and Advance Levels during the years 2012 to 2016. Research data was collected through in-depth interviews held with the heads of the sampled institutions; interest was the resource management strategies that placed schools in the academic spotlight notwithstanding the general insufficiency of resources. Responses were analysed using the process of thematic analysis, with leaning on positivism. The process was facilitated by the use of Atlas Ti 5.2 (Atlas Ti GMBH 2006). Findings revealed a number of complementary strategies employed by the schools studied, including focus on essential curricula, presence of articulated mission and focused vision, close instructional supervision, prioritizing only essential expenditures in the school budget and strict control and demand for accountability. The researcher proposed for decisions on education and school management to factor in the need to clearly define the mission and vision for education/school, revise and adapt the curriculum to current needs and scale down the number of subjects, channel effort and resources to the learning of essential curricula, provide more instructional supervisory support to teachers, etc.
\end{abstract}

Keywords - Budget Constraints, Management, Education Credits, Efficiency, Effectiveness, Sustainability.

\section{INTRODUCTION AND PURPOSE}

Educational systems in almost all countries in the world are constrained by insufficiency of resources required for smooth operation. In developing countries where the school age population constitute majority of inhabitants and where raising funds for educational development is increasingly becoming problematic, high demand for education often translate to thin spread of resources over large numbers of students. Generally, and especially in contexts where there exist large resource gaps, global recommendation has been for the available means to be used efficiently to compensate for shortages while exploring other alternative funding sources to supplement the available resources. In Cameroon, however, concerns around the management of scarce resources dominate the discussions on educational development among interest parties within and outside the education sector as problems of wastage persist, further compounding the already difficult situation and system's ability to meet commitments, set goals and objectives. This research inquired into educational resource management practices with attention on secondary education. Aim was to determine those allocation and management strategies that yield best possible outcomes at comparably lower costs, so as to propose solutions to the problems of choice that often confront educational managers and administrators when deciding on how and where to channel efforts and resources.

ISSN: 2456-7620 


\section{BACKGROUND}

\section{Overview of Cameroon's economic situation}

Cameroon is a developing country in Sub-Sahara Africa (SSA) with a population of about 24.7 million inhabitants. Classified as a middle-income economy, Cameroon's GDP measured at $\$ 38.7$ billion in 2018 and grew by $3.9 \%$ in the first half of 2019. Current account deficit stood at 4.7\% GDP as of end of June 2019, while public debt grew from GDP $30.9 \%$ in 2015 to $41.5 \%$ in 2019 (IMF, 2020). IMF warns that Cameroon is at high risk of debt distress. The country has high rates of youth unemployment and underemployment, and a large portion of its population survives on less than $\$ 1.9$ per day, particularly those in rural areas. Poverty rate was $22.3 \%$ in 2019 (World Bank, 2019).

\section{Why care for efficiency in the management of education credits?}

Over the past few decades, Cameroon like her other counterparts in SSA has witnessed an explosion in school enrolment at all levels. From 2007/2008 to 2015/2016 academic year, secondary education enrolment increased by approximately $96 \%$, from $1,125,713$ to $2,205,778$ students (according to information drawn from the Report of Analysis of Cameroon's Ministry of Secondary Education-MINESEC Statistical Data, 2012/2013 and MINESEC Statistical Yearbook, 2015/2016). As the principal guarantor of education, the government of Cameroon devotes significant share of total public spending on education to sustain educational activities in the public sector and to provide support to schools operating in the private sector, as part of the strategic axis of development of the partnership in the sector. For instance, the education sector consumed on average $14.2 \%$ of the annual executed public expenditure between the years 2010 and 2016, though this falls below the level envisioned in the Education Sector Strategy 20132020, as well as the 15 to 20 percent minimum benchmark recommended by Global Partnership for Education, the 2015 Addis Ababa Action Agenda and the 2015 Education 2030 Incheon Declaration (World Education Forum, 2015).

Nevertheless, the burden of education financing does not rest entirely on the shoulders of the government. Principal documents notably the Education Sector Strategy (Republic of Cameroon, 2013) carriers overarching policies for the education sector as stated in the Constitution, the 1998 law on the orientation of nursery, primary and secondary education and teacher training, the 2001 law on the orientation of higher education, and the Growth and
Employment Strategy Paper, etc. These policies focus mainly on promoting access and equity, improving quality and relevance, strengthening sector governance and management, and reforming education financing mechanisms. Also highlighted are the various education partners and their roles and responsibilities in the participatory support and management of the sector. These include pupils and students, parents, teachers syndicate, village development committees, alumni groups, religious bodies, business organizations, NGOs, donor countries and international organizations. A number of studies have shown the role played in educational financing by these actors. Research conducted in Fako Division of the South West Region of Cameroon for example shows the total amounts contributed by samples of various categories of subjects in support of secondary education during the 2015/2016 academic year as follows: parents $=65,468,000$ FCFA, religious organizations $=10,382,500 \quad$ FCFA, councils $=9,000,000 \quad$ FCFA, business organizations $=4,835,000 \quad$ FCFA, community leaders $=3,430,000$ FCFA, NGOs $=1,825,000$ FCFA, and school alumni=20,000 FCFA (Mekolle, 2018). For the most part, parents and households, especially poor ones spend significant portions of their incomes on education in developing countries where the policy of free compulsory education offers limited coverage. The findings of the Fourth Cameroonian Household Survey that held in 2014 shows that in the 2013/2014 school year, household spending national average were only a little less than 50,000 FCFA per student at the secondary level. Averages were 29,000 FCFA among public schools, and 99,000 FCFA among private schools. Mekolle (2019) also highlights the enormous financial implications to households in seeing their children through secondary education in Cameroon.

While persons assigned with management responsibility should always ensure that public resources are used judiciously, in times when demand for education is on a hike but when tight fiscal constraints and competing priorities limits prospects of increased public spending on education; in times when additional demands are made on taxpayers and when there is great need to rescue the drowning quality of education, it is particularly important for educational managers and administrators to demonstrate good stewardship of available resources in a way that meets the learning needs of all. Even where education budgets can be shielded from budget cuts with prospects for further fiscal stimulus, stronger commitment to efficiency can help ensure 
that the best possible outcomes are achieved with available resources (OECD, 2013a). The document, A Handbook for Teachers of Secondary and High Schools - a prominent reference tool designed to increase efficiency and rigour in the educational system emphasizes on the need for prudence with regard to school budgetary management:

The Head must run the school budget the way a "good family head" runs his/her home. S/he has to respect to the latter all the legislation that pertains to the running of a budget...S/he must never overspend and should always see to it that funds allocated for a particular projects are properly disbursed (Republic of Cameroon, 1996, p.45).

Research in most cases has shown direct correlation between educational expenditure and educational quality; the more resources are available for education in a balanced mix the better the quality of education and vice versa. Even so, resource optimization stands out as the main ingredient for sustainable high returns to investment in education. Efficient directing and coordination of resources builds confidence in parents, the educational community and aid donors and increase their willingness to make their best commitments to educational advancement. Management practices that are founded on principles of efficiency do not only reduce financial losses, but can also bring about savings in time and money that can be used to boost quality, or directed to other areas of need. Most importantly, efficient resource management supports the achievement of instructional goals and objectives and can help sustain teaching and learning activities in times of acute shortage of funds. In brief, directing the right resources to the right place at the right time in the process of human capital formation is a sine qua non to success.

Currently, there is a wave of interest from both state and none state parties in the way resources are managed, owing to increasing consciousness of the importance of education and the need for quality and equity in service delivery. Calls are being made at the local, national and international levels for governments to provide greater oversight to ensure that public resources are directed to areas where they are intended and most needed. In fact, ensuring efficiency, accountability and transparency in the way resources are spent in the education and other sectors of the economy is an integral part of government's strategy designed to achieve planned national growth and development as reflected in the Vision 2035 (Republic of Cameroon, 2009).

\section{STATEMENT OF THE PROBLEM}

Today's complex educational systems are faced by two conflicting challenges of unprecedented magnitude: that of having to serve an ever growing student population with a richly rigorous and germane education that is subjected to continuous improvement for a greater chance to compete successfully in the global economy, and having to deal with increasingly fewer financial resources than in the past. In recent years, Cameroon has witnessed a disproportionate increase in secondary school enrolment and the share of state budget allocated to the sector. While the number of registered students almost doubled in 2016 compared to what obtained in 2007, public expenditure on secondary education only increased by $48 \%$, from 166,724 million FCFA in 2007 to 246,068 million FCFA in 2016 (MINESEC Statistical Yearbook, 2015/2016). This has meant that educational institutions have had to train more students using fewer resources. All principals interviewed during the conception stage of this study noted that they worked on a tight budget basis - those for schools in the public and private sector alike (findings from an earlier simple random interview conducted by the researcher).

Rational behaviour model suggests that equipped with substantial information and understanding of the context in which education occur, educational managers and administrators faced with budget constraint would not only make wise choices as to questions of what educational cost items should be acquired at what quantity with the means available, but also ensure prudent management and efficient utilization of the resources available for education. Observably some educational institutions are making efforts in this light, however, a significant amount of crucial funds for education continue to get lost through misappropriation and inefficiency as evident in the rates of students' failure, repetition and dropout. The internal efficiency coefficient (IEC) evaluates wastage in the management of public credits in the educational system of a country. Coefficient ranges from 0 (in a system in which no students complete a given cycle) to 100 (in a system with neither repetition nor dropout). The IEC for secondary education in Cameroon in 2011 was measured at $64.25 \%$, meaning $35.75 \%$ of resources allocated to the sector were wasted in repetition and dropout (Republic of Cameroon, 2013). A survey of teachers and principals conducted in USA in 2012 shows that $78 \%$ of principals and $86 \%$ of teachers reported that managing the school budget and resources to meet school needs is challenging or very challenging for school leaders 
(MetLife, 2013). These exigencies pose a great necessity for research to come up with pragmatic, new and innovative ways by which educational managers and administrators can maximize the use of the fewer resources at their disposal.

\section{CONCEPTUAL REVIEW}

\section{Understanding Budget Constraints}

Human beings in all income quintiles, whether operating as individuals or as groups and communities with shared interest are often driven by bundles of wants which they would like to satisfy at the same time if it were possible. The wish to fulfill all wants within the shortest timeframe is however usually curtailed by the often limited means available so that having to choose what to satisfy vis-à-vis ability to pay becomes inevitable. People become financially constraint where their needs fit precisely within the means available, or where they get limited in their consumption pattern by the means at hand. In economics this is referred to as budget constraint and can be represented by the formula:

$$
p A * q A+p B * q B=Y
$$

Where: $\mathrm{pA}=$ price of item $\mathrm{A}, \mathrm{qA}=$ quantity of item $\mathrm{A}$ consumed, $\mathrm{pB}=$ price of item $\mathrm{B}, \mathrm{qB}=$ quantity of item $\mathrm{B}$ consumed, and $\mathrm{Y}=$ income.

The graph below illustrates an individual's budget constraint at various combinations of two commodities.

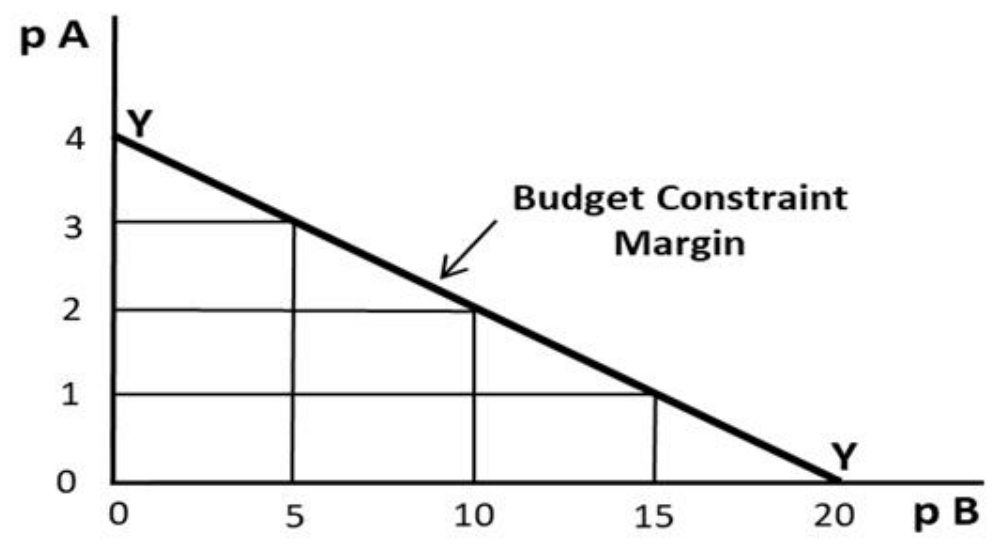

Fig.1: Budget constraint for two commodities

Source: Author, 2020

Suppose the individual has 10,000 FCFA to spend and choses to do so on commodities $\mathrm{A}$ and $\mathrm{B}$ in his need array in different quantities, if he prefers more of $A$, he will only be able to purchase 4 units of item $A$ on the vertical axis of the graph and nothing for item B as on the horizontal intercept. If however he decides to reduce the number of item $\mathrm{A}$ he buys in order to get some of $\mathrm{B}$, then he can be able to pay for 3 units of A and 5 units of B. Generally, at the lower portion of the slope $\mathrm{Y}$, the individual would be able to afford any combination of the two items, but any attempt to get both items above it cannot be possible at same market price without violating the budget constraint.

The term budget constraint has been attributed different meanings in different disciplines. Before defining the concept, it is important to understand first what a budget is. A budget refers to a statement of planned financial expenses of an organization designed to achieve its projects, goals and objectives set for a given year or period of time. Besong (2016, p.160) defines it as "a financial blueprint for the operation of an organization, including the school system, for the fiscal year". Budget constraint can be defined as a situation whereby one operates within a tight budget in which all planned expenses must fit to achieve set goals and objectives. In economics of education, it means the aggregate of all institutional visible cost items (structures, equipment, staff salaries, etc.) for which total expenses incurred fits exactly within the limits of the total budget allocated for education for a given year. Budget constraint implies zero possibility for saving, financial carry-over or cuts on institution cost items as these are all required in their 
planned quantities for the smooth operation of the educational system.

National education endeavours are often characterized by financial constraints at all levels at both demand and supply sides. In Cameroon and other developing countries where the onus of education financing weigh heavily on families, poor households, particularly those living in large cities find it difficult to bear own share of the cost of education. Their incomes are highly inadequate to cover the cost of education and other basic subsistence family needs such as accommodation and feeding. Consequently, many children, especially girls do not participate in formal education. Similarly and though listed in many cases as national priority, developing countries governments find it difficult to provide sufficient funding for the education of their citizens due to competing priorities over limited national resources and the need to ensure balanced development.

Budget constraint at the supply side of education can be temporarily overcome by means of education loans, aids, and individual schools engagement in income generation activities. Also, governments can decide to subsidize the education costs of poor households through scholarships to students and waiver on school fees and other expenses in view of sustaining their participation in education. This practice is common in many countries at the level of primary education.

\section{What is meant by Education Credits?}

Education in most countries constitutes one of the sectors of national economy. As such and like other sectors of the economy, governments provides staffing needs and assign to education at the beginning of every fiscal year a share of the national budget to support activities and operations in the sector. In the same light faith-based organizations and other private owners of educational institutions who by virtue of their contribution to educational service delivery in many countries constitute important state partners in education provides on an annual basis the personnel and funding needed for the running of own schools. These funds together with contributions from parents, students, aid donors and other private stakeholders represent what is referred to from the financial accounting perspective as education credit. The term education credit is therefore defined here as the totality of all human, financial and material resources available for education. This conceptual approach is different from education credit as commonly known, and as applied in contexts such as the USA where it has to do with financial returns to education tax given to students who are pursuing post-secondary education in college or university, in a way to assist them with tuition cost of higher education and increase their participation at that level.

\section{Efficiency in education}

Efficiency in education is a goal that is often featured in countries' education policy documents. However and though highly important and universally held as yardstick on which systems' performance should be measured, many educational managers and administrators continue to feel ambivalent about the pursuit of efficiency in education including with the worry that efforts to improve efficiency will mean trading-off the quality of education since it involves cutting expenses or minimizing costs. Very often, these feelings stem from ambiguities around the use of the concept and misunderstanding of its meaning, but also from past legacy, sometimes misconceived efforts to improve the efficiency of educational systems. It is therefore useful to shed light on the concept of efficiency as it applies to education.

Efficiency refers to the relationship between the inputs into a system and the output from the system. Inputs are the various elements that enable the education system to function properly. They include the human resources such as teachers, educational administrators and pupils, and material and financial resources such as didactic materials, structures, machineries and equipment that are required for teaching and learning. These resources (excluding pupils) when aggregated can be expressed in terms of per pupil expenditure per year. Output on the other hand refers to the results or outcomes produced as a function of the processes of the education system in relation to its goals and objectives. These include students' academic performance, graduates and the knowledge, skills and attitudes acquired from the system by these and all those who inhabit or make contacts with the system. No educational system can perform at 100 percent efficiency as there are always cases of resource wastage. Notwithstanding, an educational system is said to be efficient if it produces more desired output for a given set of resource inputs, or produce with fewer same inputs comparable levels of the required output. Efficiency in education can be seen from two perspectives: internal and external efficiency.

Internal efficiency of education is based on the link between the cost of inputs into the system and students' 
academic achievement. It is concerned with obtaining the greatest educational outputs in terms of students' learning and number of graduates for any given level of spending. The internally efficient educational system is one which maximizes students' learning and turns out graduates without wasting any student-year or without dropouts and repeaters (Akinwumiju, 1995). In other words, an educational system is considered to be internally efficient if the wastage rate of the system is low in terms of the number of repeaters, dropouts and those who actually complete a particular school cycle without acquiring some of the skills that the system set forth to teach at that level.

External efficiency of education is defined as a measure of the extent to which the knowledge, skills and attitudes taught by the educational system meets students' aspirations and the needs of the society. The ability of school leavers to integrate into the society and effectively contribute to efforts aimed at resolving societal challenges and improving the general wellbeing, or of graduates to be absorbed and perform well in the job market represent some of the most important parameters of external efficiency. These productive abilities are the outcome of seeing students through a given level of schooling, which goes beyond immediate outputs in terms of maximum students' learning and number of graduates using a certain amount of resources.

An educational system may exhibit attributes of internal efficiency, but such efforts would be watered down if the curriculum does not resonate with the socio-economic needs of the society. Unfortunately, the problem of poorly adapted curriculum appears to be one of the greatest challenges faced by Cameroon's educational system and those of many other African countries as documented by scholars such as Nsamenang and Tchombe (2011). It is therefore imperative to adopt a holistic approach when designing efforts aimed at improving efficiency of education.

\section{THEORETICAL FRAMEWORK}

This paper was based on the philosophical reasoning advanced within the framework of the Rational Choice Theory (RCT). RCT is a global term for a variety of causal explanation contributory models that consider social phenomena as outcome of the deliberate actions of individual actors that can be qualified as rational. Associated with the economic philosopher Adam Smith (1776), the theory has as main assumption the belief that as rational beings and when provided with adequate information, individuals would invest in rational calculations and settle for one or more options they believe would yield results that optimize their preferences, given the constraints or limitations imposed by the situation (Rational behaviour). The key elements of the theory are individual preferences, beliefs, and constraints. 'Preferences' means the positive or negative evaluations individuals attach to the possible outcomes of their actions; 'beliefs' denotes perceived causeeffect relations, including the perceived likelihood with which an individual's actions will result in different possible outcomes; meanwhile 'constraints' define the limits to the set of feasible actions (Wittek, 2013). For instance, the amount of credit available for Parent Teacher Association of a given school imposes a budget constraint on the number of qualified teachers that can be recruited by the said school under PTA payroll.

The issues discussed in RCT are relevant not only to management in the education sector, but to the sustainable running of societies as a whole. RCT can be said to be critical in informing management decisions that constitute backdrop to the successes associated with many organizations around the world. The theory infers that faced with tight resource situations and conscious of the realities of the context in which education occur, educational managers and administrators, when making decisions, would select courses of action that optimize available resources and maximize school performance outcomes.

\section{REVIEW OF EMPIRICAL LITERATURE}

As education resource base continue to shrink, scholars and educational researchers in various countries are turning attention to looking at how scarce resources can be effectively managed at school, divisional, regional and national levels to optimize desired output. A school survey conducted by Dagget and team in USA found some schools that were able to sustain high student academic performance at low cost. The researchers used the Effectiveness and Efficiency Framework (E/E Framework) tool to evaluate and analyse how the innovative schools had done at both improving student performance and reducing costs (Dagget, 2014). The E/E Framework tool was developed in the form of a four-quadrant schematic drawing with quadrant $\mathrm{A}$ representing High cost/Low performance, quadrant B Low cost/Low performance, quadrant C High cost/High performance and quadrant D Low cost/High performance. 
The research recommended schools and districts to give priority to initiatives in quadrant $\mathrm{D}$ including coordinating professional development with graduate degrees, slightly increasing class size with a focused professional development program, and using team work.

In another paper, Gendron and Faherty (n.d.) shared their experience while serving as superintendent and assistant superintendent of the Windham School Department in Maine, USA. The educational experts recounted how confronted by resource crisis amidst a period of economic recession and at the dawn of education policies such as No Child Left Behind, they successfully guided a team of school administrators at various levels through an efficient and sustainable education management process that balanced fiscal prudence with high student engagement and academic performance. The process centered basically on identification of best practices which were then compared to available resources before arriving at decisions that optimized resources and maximized the achievement of district performance goals. Strategies that emerged include clear articulation of the district mission and vision, analysis of students' academic performance data to determine areas of success and additional resource need, etc.

Generally, much of the meager literature available on this subject presents strategies purportedly linked to efficient resource management without indicating any methodological approaches used to arrive at the findings. This study adopted a more scientific approach which was hoped would lead to findings that can be more credible and reliable. Also, by studying what obtains in Cameroon, it was hoped that findings would provide insight which can be adapted in other countries, particularly those in SSA where the problem of education resource management is acute but where little or no research effort has been directed at resolving the issue.

\section{METHODOLOGY}

This study used the survey research design. Specifically, the qualitative approach was used. This approach requires participants who are versed with or knowledgeable of the issue under study to directly express without distortion their viewpoints on the subject matter. This is often done by way of questionnaires, in-depth interviews, focused-group discussion, observations and other similar methods. The data required for this study was collected through interviews with the respondents.
Review of statistics obtained from the Service of Results and Archives, of the Sub Directorate of Examinations, Concours and Certification, of the Cameroon's South West Regional Delegation of Secondary Education identified 18 secondary schools, mostly denominational and mainly in the North West and South West Regions that consistently scored above 95\% in GCE Ordinary and Advance Level Examination during the years 2012 to 2016, before the outbreak of the ongoing armed conflict in the Anglophone regions that has seriously affected educational activities in the area. Only schools that registered from 10 candidates upwards at either level of the exams were considered. Pass rates in the end of course examination were seen to be a satisfactory measure of efficiency of resource management - at least as concerns internal efficiency. The findings of preliminary inquiries from a sample of heads of 30 secondary schools in Fako Division of the South West Region of Cameroon unequivocally showed that schools were operating on an insufficient budget basis. What worked for the 18 educational institutions that sustained high student academic performance during the period under consideration, of the over 1000 English-speaking and bilingual colleges found in the country was therefore of paramount interest to the researcher. Of the schools identified, a representative sample of 13 was selected for the study using the simple random sampling technique. The sample was selected based on both design and study purpose. Qualitative studies because of their in-depth-exploratory nature and complex stages and time-consuming phases of data processing necessitates the use of small samples, however considering the target population, the time frame, the resources available, and the diversity of the opinions sought by the research (Nana, 2018). Face-to-face or telephone interviews were held with the heads of the 13 secondary schools with focus on whether or not there was a mission statement and the managerial initiatives behind school's success. Telephone interview was adopted in cases where COVID-19 scare and the insecurity could not allow for face-to-face interview.

Data analysis was done using the process of thematic analysis with leaning on positivism. Respondents' ideas where grouped under umbrella phrases that emerged from field interview notes and transcriptions from telephone interview recordings. An idea advanced was considered relevant whether shared by two or more school heads or held by just one of them. In other words, the importance of an idea was accorded precedence over its frequency or 
grounding, though the frequency was a major indicator of emphasis. Direct quotation from subjects has been shown in the findings for each strategy advanced. The process of data analysis was facilitated by the use of Atlas Ti 5.2 (Atlas Ti GMBH 2006).

\section{FINDINGS}

Most of the schools studied reported being guided by an articulated mission and or motto upon which school processes and performance were anchored. The following excerpts were drawn respectively from mission statements of three education authorities whose institutions prominently featured among the schools studied.

We value and cherish most, an educational system that fosters a healthy balance between faith and reason; the formation of the whole person; cultivation of virtue; a social option for the poor and marginalize...The vision for schools... (i) Create a culture of continuous school improvement and sustainability; (ii) Celebrate excellence and (iii) Cultivate a culture of Assistance at all levels.

Education Authority shall strive to: 1. Provide a devoted, sustainable and affordable high quality education to all, at all times within available resource...5. Fulfill this mission within a deep commitment to human dignity and basic human rights and the moral and ethical obligations of the education profession in Cameroon.

The general purpose for education shall be to train children for their intellectual, physical, civic and moral development and their smooth integration into society bearing in mind prevailing economic, socio-cultural, political and moral factors.

With regard to what worked for successful schools, principals reported a number of initiatives as presented in Table 1 below.

Table 1: Thematic analysis of principals' responses on resource management strategies used in schools

\begin{tabular}{llll}
\hline Themes & \multicolumn{2}{c}{ Grounding } & Sampled quotations \\
\cline { 2 - 3 } & $\mathrm{n} \%$ & & $\begin{array}{l}\text { 'We encourage meticulousness in the teaching of vital aspects of the } \\
\text { curriculum. We make regular consultations with the examination board to } \\
\text { get the most recent development on examinations and syllabuses. This } \\
\text { information provides guide and helps the teachers to avoid spending time on } \\
\text { trivialities.' }\end{array}$
\end{tabular}

'Teaching/learning activities are strictly child-centred. Our teachers have

Using student-centred teaching

Close instructional supervision

Using financial motivation schemes been trained and use those methods of teaching that places the child at the centre of instruction.'

'We always verify to ensure that teachers are effectively present in the classrooms during lesson hours. Teachers show proof of lesson preparedness from their lessons plans which must contain clear learning objective.'

'Besides the general motivational allowance given to all teachers on a periodic basis in recognition of their hard work, we use various allowance schemes such as class masters allowance, game master allowance, socials master allowance, etc. Almost all teachers are put on some kind of special allowance.' 


\begin{tabular}{|c|c|c|}
\hline \multirow{2}{*}{ Themes } & Grounding & \multirow[t]{2}{*}{ Sampled quotations } \\
\hline & $\mathrm{n}$ & \\
\hline
\end{tabular}

Ensuring teachers

professional

1292

development

Using peer learning

groups

$12 \quad 92$

Recruiting well qualified teachers

11

85

Timely payment of teachers' salaries

Articulated mission

10

Prioritizing only

essential expenditures

10

77

Strict control and

demand for

10

77

accountability

Regular evaluation of teachers' effectiveness
'We invest a lot on in-service training programmes. We have specialized personnel whom we have trained to man these programmes. They organize workshops with teachers on lesson notes preparation, management of complex tasks, classroom management, setting and marking of exams, etc.'

'Students learning within peer groups have been very instrumental to the success of all. We stratify the students by academic ability and mix them into small heterogeneous learning groups under the supervision of teachers.'

'Teachers must meet certain minimum standards for recruitment; they should be able to teach in at least two subjects, have a Bachelor's degree and show proof of professional training and experience. Most of our teachers have written resource materials on their subjects.'

'We ensure that teachers receive timely and regularly what they signed to be paid in their employment contracts. This motivates and increases their commitment to work.'

'The education authority has a mission statement that applies to all our educational institutions across the country. The statement provides for high quality standards which all teacher and students are expected to adhere to.'

'We work strictly within the confines of our budget and streamline expenditure in a way that wastage is minimized. We do so by directing our money to only important expenditures which include staff salaries and students' feeding and utilities.'

'There is strict control and demand for accountability from hierarchy. Meticulous control is done that you do not want to make errors, and there is really no room for errors. You need something, you submit your demand to hierarchy and how much it cost; they give you the money. At the end you have to produce an expense receipt to reconcile with what you initially requested.'

'We have a culture of regularly evaluation of teachers' commitment and effectiveness. We do this from the perspective of the students taught by individual teachers. Students fill the Teacher's Assiduity Form and hand it to the administration for further treatment.' 


\begin{tabular}{|c|c|c|c|}
\hline \multirow{2}{*}{ Themes } & \multicolumn{2}{|c|}{ Grounding } & \multirow[t]{2}{*}{ Sampled quotations } \\
\hline & $\mathrm{n}$ & $\%$ & \\
\hline $\begin{array}{l}\text { Revising lessons with } \\
\text { students }\end{array}$ & 10 & 77 & $\begin{array}{l}\text { 'We ensure that syllabus are covered on time and that teachers adequately } \\
\text { revise lessons with students prior to examinations.' }\end{array}$ \\
\hline $\begin{array}{l}\text { Investing time on } \\
\text { learning }\end{array}$ & 8 & 61 & $\begin{array}{l}\text { 'We engage students in agriculture and school-based projects such as } \\
\text { production of sanitizers, soap, detergents, mushrooms and corn beer. The } \\
\text { essence is to prepare those who will be unable to proceed to higher education } \\
\text { to be able to do something to survive in the society. Aside this, we ensure } \\
\text { that students focus on learning and not burdened with things that do not } \\
\text { benefit them.' }\end{array}$ \\
\hline $\begin{array}{l}\text { Improving school } \\
\text { infrastructure }\end{array}$ & 7 & 54 & $\begin{array}{l}\text { We always try to give our campus a new face lift. Students like to find that } \\
\text { something is new. We just built a new hall and added protectors on windows } \\
\text { of some of the classes to curb students' indiscipline and focus on } \\
\text { teaching/learning.' }\end{array}$ \\
\hline $\begin{array}{l}\text { Adequate counselling } \\
\text { and reorientation } \\
\text { services }\end{array}$ & 7 & 54 & $\begin{array}{l}\text { 'We have an effective counselling service in place to ensure that students are } \\
\text { of good conduct and understand and adhere to school rules and regulations. } \\
\text { We also reorient students on programmes to follow; we may switch them } \\
\text { from grammar to commercial education as may be deemed necessary.' }\end{array}$ \\
\hline Use of remedial teaching & 7 & 54 & $\begin{array}{l}\text { '...for example, there are some children that we receive from the primary } \\
\text { school who cannot spell or read well. We select such children and arrange } \\
\text { with the English Language teachers to drill them on sound building and } \\
\text { shapes of letters. We do this and they improve after sometime. }\end{array}$ \\
\hline Compulsory prep & 6 & 46 & $\begin{array}{l}\text { 'We have compulsory preps in the evenings and we are always there to } \\
\text { follow up the students so that they effectively study for at least two hours.' }\end{array}$ \\
\hline $\begin{array}{l}\text { Having teachers handle } \\
\text { related subjects }\end{array}$ & 5 & 38 & $\begin{array}{l}\text { 'We ensure that teachers who handle junior classes teach at least one related } \\
\text { subject. For example, a teacher who is teaching Biology will also teach some } \\
\text { Chemistry. But for the higher classes, its one teacher, one subject.' }\end{array}$ \\
\hline
\end{tabular}

$\mathrm{N}=\mathbf{1 3}$

The bar chart that follows presents a graphic view of the above information. 


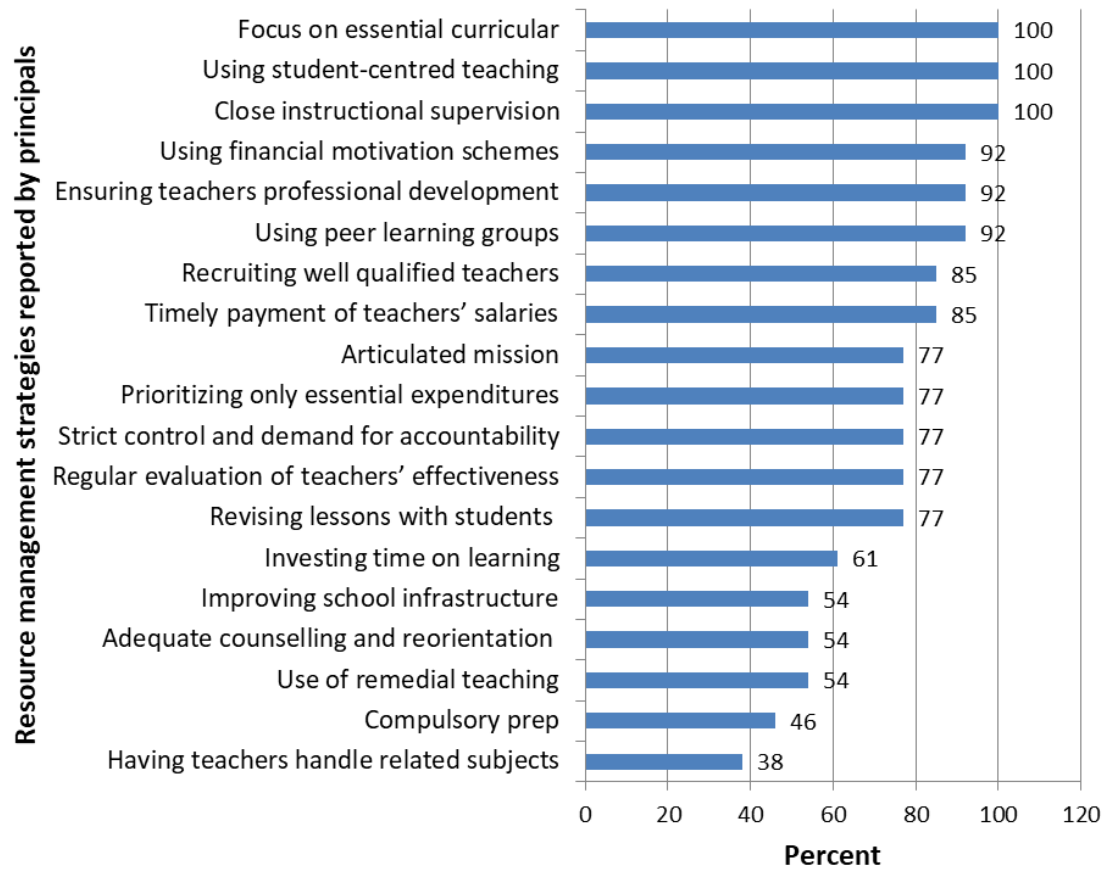

Fig.2: Efficient resource management strategies reported - by percentage of responses

Principals were unanimous in the belief that school performance outcome was based chiefly on the resource management strategies employed. They all reported (100\%) that the school focused on essential curricula, used teaching methods that place students at the centre of instruction, and carried out close instructional supervision to ascertain that teachers were doing their work correctly and on time. These were followed by reports of school directing resources to teacher professional development, use of financial motivation schemes and peer learning groups - each with a weight of $92 \%$. Principals also reported (85\%) that school recruited well qualified teachers and ensured salaries were paid on time. Furthermore, school heads indicated that there was effective presence of a mission statement that guides school operations and that their school budgets prioritized only essential cost items - mainly teachers' salaries, student feeding and utilities. These, as well as reports of strict control by hierarchy and demand for accountability on how resources were spent, regular evaluation of teachers, timely coverage of syllabus and continuous revision until examinations weighted $77 \%$ each. Also reported were schools spending more time on learning, devoting resources for infrastructural facelift, having an effective counselling and student orientation service, using remedial teaching, compulsory preps and having teachers handle more than one subject.

\section{DISCUSSION}

The findings of this study converge to a certain extent with those of other researchers like Dagget and team (Dagget, 2014), and the efficient resource management strategies reported by Gendron and Faherty (n.d.), particularly as concerns the use of professional development programmes and team work, articulated mission, and mapping and assisting students with extra learning needs. Judging from the perspective of the individual strategies reported, a number of earlier researches support the findings that defining the mission for education and selling the vision through communication and leadership actions that create supportive teaching/learning environments are hallmarks of effective schools (Brookover \& Lezotte, 1979; Edmonds, 1982). Peer learning and other alternative delivery methods like self-instruction where used Lewin and Caillods (2001) affirms could all reduce unit cost without necessarily diminishing quality.

Reports on supervision and evaluation of teachers suggest that systems that strive for teacher effectiveness and 
career advancement through such practices as peer review of lesson plans, lesson observation by principals and students' appraisal of teachers performs at greater efficiency. This is consistent with the multiple research findings (Usman, 2015; Namunga, 2017) that show strong relationship between such instructional supervision strategies and teachers' performance and students' academic achievement, and the view by OECD (2013b) that practices that seek written feedback from students regarding lessons, teachers or resources are characteristics of successful school systems.

Similarly, practices that involves raising class sizes to manageable levels and directing resources to teachers' professional development programmes that centers on setting smart instructional objectives for students, managing large class sizes and multiple tasks and subjects as reported should have significant positive implications on costs and systems performance. This aligns with the general trend of evidence that shows weak relationship between small classes and better performance (Ehrenberg et al., 2001), and those that have documented the strength of regular workshops and related experiences in enhancing teachers' practices and professionalism (Falk, 2001; Grosso de Leon, 2001).

Coordinating well qualified teachers with performance-based financial motivation schemes as trajectory for effectiveness can be substantiated by the evidence which suggest that the quality, rather than the number of teachers available is more important (OECD, 2010), and the findings which showed better performance by students attending schools whose teachers participated in programs that used student performance-based financial incentives, as compared to students in comparison schools (Hudson, 2010). Improving physical infrastructure on the other hand helps prevent the adverse effects which insufficient or poor structures usually leave on learning. More time on teaching and learning supports the findings by (OECD, 2013b) which showed positive relationship at the school level between the time students spend learning in and after school and their academic performance - the same conclusions arrived at by researchers such as Clark and Linn (2003) and Smith (2002).

\section{CONCLUSION AND RECOMMENDATIONS}

Managing to make the most out of limited resources is generally a daunting task for those entrusted with authority and responsibility to direct the affairs of organizations such as educational institutions. There is no exhaustive blueprint; no steady strategies to be employed to bring about desired outcomes. However, in embarking on any course of action with financial and other resource implications, educational managers and administrators should be able to address four simple, interconnected but pertinent questions: why, what, where, and how. 'Why' has to do with seeking to understand the rationale for the deployment or use of a given stock of educational resources, and this should of course be rooted on the goal of effective teaching/learning and high student academic performance. Questions on 'What' requires careful and detailed analysis of the quality and quantity of resources-human, financial and material available for education for the purpose of informed allocation and rationing. 'Where' on its part should concern with understanding areas with critical resources need for targeted allocation and to safeguard that resources are not directed to areas where they are underutilized, while 'How' involves the sureness of the technical knowledge of how resources should be coordinated to achieve the desired outcomes as well as how system performance shall be evaluated for improvement. In addition to these and more importantly, the findings of this study, like those of earlier works highlights some not very farfetched initiatives that can be considered and adapted in educational systems in different contexts to bring about the needed change. On the basis of the findings and in line with the relevant literature this paper suggests for decisions on education and school management to consider the following strategies.

Clearly define the school's mission and vision. No organization can operate effectively without a clear mission and a focused vision that guides its activities. The same applies to educational institutions and is true for schools of all types and levels. In Cameroon, the mission for education is spelt out in Section 4 and 5 of Law No.98/004 of 14 April 1998 on the orientation of nursery, primary and secondary education and teacher training, and Article 2 and 6 of Law No.005 of 16 April 2001 on the orientation of higher education in the country. The problem, especially at the primary and secondary levels is that relevant legislations are almost inaccessible and therefore unknown to a large majority of stakeholders who are charged with the implementation of actions towards the achievement of set goals and objectives. Where inexistent or ambiguous, it is imperative for policy makers and educational authorities in consultation with the other stakeholders to develop clear statements of purpose for education which schools should follow. Statements that prioritize efficiency and high student 
learning accompanied by clear communication and leadership actions that create enabling work environments should be more rewarding.

Revise and adapt the curriculum to current needs and scale down the number of subjects. As the global society evolves to a knowledge based economy with increasing dependence on information manufacture and processing and other high level scientific and technological knowledge, there is an urgent need for Cameroon and other developing countries to overhaul the curriculum which in the most part runs antithetical to students' needs and aspirations and to global knowledge trends. Only subjects that are judged to be most relevant in developing the required competencies should be considered. Reducing the number of subjects that students have to learn should lessen pressure on the overcharged curriculum, enhance early specialization in relevant knowledge fields and allow for more time and resources to be concentrated on the learning of essential knowledge and skills. It would also reduce the number of teachers and hence salaries and other personnel costs.

Channel effort and resources to the learning of essential curricular. It is cost-effective in a context where educational resources are highly constrained but where the curriculum is loaded with not so very useful content to direct resources to the learning of only key area of knowledge in the various subject domains. Schools should know the skills that are most demanded by employers and liaise with the various examination bodies to determine those areas where students' knowledge is regularly tested to inform decision as to where to focus attention.

Recruit only the required number of teachers per subject and maximize the use of staff. Personnel costs constitute the largest expenditure item in secondary education budgets. As such inefficiencies in teacher recruitment and deployment, often, are a major cause of high per student cost. Reviewing staffing policies to ensure that some schools or subject departments are not over-manned while others are understaffed is a very effective way of utilizing personnel and reducing wastage. Schools should assign teachers with full instructional workload and set up follow-up mechanisms to ensure commitment to duty.

Provide more instructional supervisory support to teachers. Educational administrators must view teachers as different from each other and provide the supervisory support needed to help staff develop their competencies and attain heights of professional development that enables them adapt well in an increasingly challenging and ever changing knowledge society. Principals and other senior staff should constantly follow up to ensure that teachers effectively prepare and deliver their lessons. Periodic evaluation of teachers should help in identifying areas of progress and where there is need for intervention. Regular workshops and in-service training programmes that addresses subjects such as knowledge and use of ICT, formulation of smart and fascinating lesson objectives, development of lesson notes, management of diversity in the school setting, management of complex tasks, classroom management, etc. are worthy endeavours that should help teachers grow professionally and increase students' performance.

Slightly increase class sizes where figures are low. In Cameroon the standard class size for secondary education is 50 students per class, but government policy is for the number to not exceed 60 students. However, in schools in the major towns where student intake is high compared to accommodation capacity, class sizes often exceed this figure and can extent up to 100 students especially at lower grades (situation prior to the outbreak of COVID-19). Where possible and particularly in countries where the prescribed figures are lower, raising class sizes slightly higher should reduce the number of student groupings for instructional purposes at any given grade and consequently the number of teachers per subject per grade, and expenditure on the purchase of instructional materials. Quality can be safeguarded by directing resources to workshops with teachers that centers on large class management.

Increase the amount of time spent on learning. It is likely that one would master an activity which they spend more time on. Therefore schools should invest more time in the teaching and learning of the essential curricular, and engage less in those activities that do not actually contribute to advancement in students' learning and institutional progress. Administrative oversight should ensure that teachers respect their teaching slots on the timetable and that students are effectively occupied during lesson hours. Also, students should be regularly assigned with afterschool activities such as homework and other learning tasks, and any leftover time after syllabus have been covered should be spent on lessons review with students.

Establish peer learning groups that incorporate aspects of scaffolding. Schools could harness from differences in students' academic potentials and develop pedagogical methods that encourage and allows for self-instruction and peer learning within mix ability student groupings headed by 
high ability students with proven fortitude. The idea is that learning is best aided through collaborating with someone, especially a peer who has more knowledge about the task and helps divide it into smaller, more manageable pieces. This practice would not only reduce instructional cost where teachers are paid hourly but would also build students' capacities and help them emerge to levels were they can effectively learn more challenging tasks unassisted.

Coordinate automatic promotion with counselling and remediation. Repetition and drop-out constitute the most common ways by which scarce educational resources are wasted. They increase per unit cost and diminish the learning chances available for other students, aside the psychological implications associated with repeating a class. Student failure is often caused by a constellation of inherent psychological, home background and in-school factors. On this note, schools are advised to not 'pontius pilate' and use class repetition as a means to address students underlying learning challenges. Rather effective counselling and remedial instruction should be provided to needy students to help them improve upon their learning and progress to the next grade with their peers. This should be accompanied by measures that address in-school factors that play on students learning such as teaching methods employed, actual time spent on tasks, teachers' prejudices towards students, quantity and quality of learning materials, curricular appropriateness and the conditions under which education occurs.

Limit educational expenditure to only essential cost items. Teacher salaries and meals and utilities (as applied to boarding schools) should be prioritised and effort should be directed at reducing associated expenses without undermining quality. Salary costs could be reduced by preparing teachers to handle two or more secondary education subjects, and by recruiting unemployed university graduates who accepts relatively lower salaries than those of trained teachers but who are provided with regular on-thejob training for quality, and shown prospects for professional development. Also, cost of meals can be reduced by engaging students in some agricultural activities where they acquire relevant contextual survival skills and produce crops like cereals and vegetables that are consumed in school.

Increase calls for accountability and external control missions. As corruption increasingly manifest in educational systems, it becomes absolutely necessary to provide the support needed to help those entrusted with resources to use them as intended. School level structures like Finance

ISSN: 2456-7620

https://dx.doi.org/10.22161/ijels.55.67
Management Committees and Parent-Teachers Associations should be set up or strengthened to provide the necessary checks and balances and ensure that resources are directed only to areas where they yield the most benefit. Also, clear statements of account on the use of resources should be requested at the end of each school term, biannually, or as may be deemed necessary. These should be followed by control missions to check that money is actually spent as indicated and in accordance with agreed plans and actions. More still, practices whereby schools are financed based on academic performance should increase performance incentives, trigger more commitment by stakeholders, promote greater transparency and accountability and improve educational quality and efficiency in resource management.

\section{REFERENCES}

[1] Akinwumiju A. (1995). Educational planning statistics and models. Center for External Studies.

[2] Berry, B., Daughtrey, A., and Weider, A. (2010). Teacher leadership: Leading the way to effective teaching and learning. Center for Teaching Quality.

[3] Besong, J.B. (2016). Educational management perspectives for students and practitioners in Cameroon. Presprint Plc.

[4] Brookover, W.B. and Lezotte, L.W. (1979). Changes in school characteristics coincident with changes in student achievement. Michigan University Press.

[5] Clark, D. and Linn, M.C. (2003). Designing for knowledge integration: The impact of instructional time. Journal of the Learning Sciences, 12(4), 451-493.

[6] Dagget, W.R. (2014). Effectiveness and efficiency framework: A guide to focusing resources to increase student performance. International Center for Leadership in Education.

[7] Edmonds, R.R. (1982). Programs of School Improvement: An Overview. The Association for Supervision and Curriculum Development.

[8] Ehrenberg, R.G., Brewer, D.J., Gamoran, A. and Willms, J.D. (2001). Class size and student achievement. Psychological Science in the Public Interest, 2(1), 1-30.

[9] Falk, B. (2001). Professional learning through assessment. In Lieberman, A. and Miller, L. (Eds.), Teachers caught in the action: Professional development that matters. Teachers College Press.

[10] Gendron, S. and Faherty, A. (n.d.). Managing resources to focus on student performance: A case study of an efficiency and effectiveness review process. International Center for Leadership in Education. 
[11] Global Partnership for Education (2018). GPE's Engagement on Domestic Financing for Education. Global Partnership for Education.

[12] Grosso de Leon, A. (2001). Higher education challenges: New teacher education models for a new century. Carnegie Corporation of New York.

[13] Hudson, S. (2010). The effects of performance-based teacher pay student achievement. https://economics.stanford.edu/site/default/file/publication/hu dson_hthesis2010.pdf

[14] IMF. (2020). Cameroon. Fifth review under the extended credit facility arrangement and request for a waiver of nonobservance of a performance criterion and modification of performance criteria. IMF Country Report No. 20/48. World Bank.

[15] Lewin, K.M. and Caillods, F. (Eds.) (2001). Financing secondary schools in developing countries: Strategies for sustainable growth. UNESCO International Institute for Educational Planning.

[16] Mekolle, P.M. (2018). Private Financing and Access to Secondary Education in the South West Region of Cameroon: A Situational Analysis and Strategies for Improvement (Unpublished doctoral dissertation). Faculty of Education, University of Buea.

[17] Mekolle, P.M. (2019). Towards inclusive education: Reconciling household obligatory financing and the problem of access to secondary education in Cameroon. International Journal of Trend in Scientific Research and Development, 3(3), 1634-1644.

[18] MetLife. (2013). The MetLife survey of the American teacher: challenges for school leadership. MetLife, INC.

[19] Namunga, N.W. (2017). Effects of supervision of instructional practices on teaching and learning in secondary schools in Kenya. International Journal of Scientific and Research Publications, 7(2), 418-427.

[20] Nana, C. (2018). Research methods and applied statistics: Beginners and advanced learners ( $4^{\text {th }} \mathrm{ed}$.). GOOAHEAD.

[21] Nsamenang, A.B. and Tchombe, T.M.S. (2011). Handbook of African educational theories and practice: A generative teacher education curriculum (Eds.). Human Development Resource Centre (HDRC).

[22] OECD. (2010). PISA 2009 results: What makes a school successful? Resources, policies and practices (Vol. IV). PISA, OECD Publishing.

[23] OECD. (2013a). OECD review of policies to improve the effectiveness of resource use in schools (School resource review). OECD.

[24] OECD. (2013b). PISA 2012 results: What makes schools successful? Resources, policies and practices (Vol. IV). PISA, OECD Publishing.

[25] Republic of Cameroon. (1996). A Handbook for Teachers of Secondary and High School. Bookman Prints.
[26] Republic of Cameroon. (2009). Cameroon vision 2035. Ministry of the Economy, Planning and Regional Development.

[27] Republic of Cameroon. (2013). Document de stratégie du secteur de l'education et de la formation 2013. Working paper.

[28] Smith, A. (1776). An inquiry into the nature and causes of the wealth of nations. William Strahan/Thomas Cadell.

[29] Smith, B. (2002). Quantity matters: Annual instructional time in an urban school system. Educational Administration Quarterly, 36(5), 652-682.

[30] Usman, Y.D. (2015). The impact of instructional supervision on academic performance of secondary school students in Nasarawa State, Nigeria. Journal of Education and Practice, 6(10), 160-167.

[31] Wittek, R. (2013). Rational choice theory. Retrived from https://www.researchgate.net/publication/281206368.

[32] World Bank. (2019). Sub-Sahara Africa macro poverty outlook: Country-by-country analysis and projections for the developing world. World Bank.

[33] World Education Forum. (2015). Education 2030 Incheon Declaration and Framework for Action for the implementation of Sustainable Development Goal 4. ED2016/WS/28. UNESCO. 